\title{
Mentorship of US Medical Students: a Systematic Review
}

\author{
Amy H. Farkas, $M D, M S^{7}$, Jill Allenbaugh, $M D, M S^{2}$, Eliana Bonifacino, $M D, M S^{3}$, \\ Rose Turner, MLIS ${ }^{4}$, and Jennifer A. Corbelli, MD, $M S^{3}$
}

'Division of General Internal Medicine, Medical College of Wisconsin, Milwaukee VA Medical Center, Milwaukee, WI, USA; ${ }^{2}$ Division of General Internal Medicine, Lewis Katz School of Medicine at Temple University, Philadelphia, PA, USA; ${ }^{3}$ Division of General Internal Medicine, University of Pittsburgh School of Medicine, Pittsburgh, PA, USA; ${ }^{4}$ Falk Health Science Library University of Pittsburgh, Pittsburgh, PA, USA.

BACKGROUND: Mentoring of medical students remains a core pillar of medical education, yet the changing landscape of medicine has called for new and innovative mentoring models to guide students in professional development, career placement, and overall student well-being. The objective of this review is to identify and describe models of mentorship for US medical students.

METHODS: We searched PubMed, PsycINFO, Education Resources Information Center, and Cochrane Databases of Systematic Reviews following PRISMA guidelines. We included original, English-language studies of any research design including descriptive studies that described a mentorship program at a US medical school designed for medical students.

RESULTS: Our search yielded 3743 unique citations. Thirty articles met our inclusion criteria. There was significant diversity of the identified programs with regard to program objectives and size. The traditional dyad model of mentorship was the most frequently cited model, with a combination of models (dyad and group mentorship) cited as the second most common. Outcome measures of the programs were largely survey based, with satisfaction being the most measured outcome. Overall, satisfaction was highly rated throughout all the measured mentoring programs. Seven programs provided objective outcomes measures, including improved residency match data and increased scholarly productivity. The programs with objective outcomes measures were smaller, and 6/7 of them focused on a specific clinical area. Five of these programs relied on the traditional dyad model of mentorship. Cost and faculty time were the most frequently cited barriers to these programs.

DISCUSSION: Our review demonstrates that mentoring programs for medical students can positively improve medical school satisfaction and career development. These results underscore the need for continued innovative mentoring programs to foster optimal student development in the setting of the increasingly competitive residency match process, growing expectations about student research productivity, and the national focus for overall student wellness.

KEY WORDS: mentoring; medical; students; review.

Electronic supplementary material The online version of this article (https://doi.org/10.1007/s11606-019-05256-4) contains supplementary material, which is available to authorized users.

Received August 14, 2018

Revised February 6, 2019

Accepted July 3, 2019

Published online September 4, 2019
$\mathrm{J}$ Gen Intern Med 34(11):2602-9

DOI: $10.1007 / \mathrm{s} 11606-019-05256-4$

(c) Society of General Internal Medicine (This is a U.S. government work and not under copyright protection in the U.S.; foreign copyright protection may apply) 2019

\section{INTRODUCTION}

Medical students face unique challenges during their education. They must assimilate into the medical community while confronting the multifaceted demands of medical education. These challenges can be facilitated through effective mentoring. Medical student mentoring has been associated with easier adaptation to the learning environment ${ }^{1}$, improved satisfaction with career advising ${ }^{2}$, and increased research productivity ${ }^{3}$. Additionally, the Liaison Committee on Medical Education (LCME) requires schools to have "an effective career advising system" and programs to "promote [medical students] wellbeing." The data also suggest that medical students consider mentorship important to their education; however, only about a third of medical students report having a mentor ${ }^{5}$.

In response to these growing imperatives, medical schools have been forced to develop innovative programs to guide students throughout their medical school careers. Two previous reviews have reported on medical school mentoring programs through $2008^{6,7}$. In the last decade, myriad new programs have been created to keep pace with the changing needs of medical students, including the increased competitiveness of the residency match process ${ }^{8}$.

The purposes of this review are to identify and describe models of mentorship for US medical students, to summarize the benefits and/or disadvantages of each, and to assess barriers to mentorship. Our definition of mentorship for this review is "a developmental partnership in which knowledge, experience, skills, and information are shared between mentor(s) and mentee(s) to foster the mentee's professional development and, often, also to enhance the mentor's perspectives and knowledge."

\section{METHODS}

\section{Search Strategy and Study Selection}

We searched PubMed including Medline (1966-present), PsycINFO (1957-present), the Education Resources Information 
Center (ERIC) (1966-present), and the Cochrane Database of Systematic Reviews (1992-present) following the Preferred Reporting Items for Systematic Reviews and Meta-Analysis (PRISMA) guidelines to identify studies that describe mentorship programs for medical students. Additionally, the reference lists of previous reviews on this topic were hand-searched for any further papers meeting our inclusion criteria. A formal quality assessment of manuscripts was precluded, as neither the Cochrane Risk of Bias nor the Newcastle Ottawa Scale can be applied to the only type of study (descriptive) that exists in the mentorship literature. Search strategies were developed with a health sciences librarian (RT). Using each database platform's subject headings and search fields, various combinations of the following subject headings and keyword groupings were investigated: mentoring, academic medicine, physicians (see Appendix online for full search strategy in the Electronic Supplementary Material). When building the search strategy, a wide range of specialty terms was tested. Only specialty terms that added unique records to the set were included in the final search strategy. Searches were finalized on June 27, 2017. Two reviewers (JA and AF) independently evaluated all records for eligibility using DistillerSR, a web-based systematic review data management system. Any discrepancies regarding inclusions were resolved by group consensus, and consultation with the senior author (JC). Additionally, in order to ensure that the review was up-to-date, the search was re-run on November 6 , 2018. One additional study published after our original search date met inclusion criteria.

\section{Study Eligibility Criteria}

We included original, English-language published studies that met the following inclusion criteria: (1) described a mentorship program, exclusive of mentoring for a specific/procedural skill or scholarship/research program, (2) described a program designed for medical students or provided results for medical students, and (3) described a program conducted in the USA. Given the qualitative and/or descriptive nature of the majority of the mentorship literature, we decided a priori to include all research designs in the interest of generating a comprehensive review of this literature. Full inclusion and exclusion criteria are described in our protocol registered on PROSPERO and can be accessed at https://www.crd.york.ac.uk/PROSPERO/ display_record.php?RecordID=83451

\section{Data Abstraction}

Two study authors (JA and AF) independently abstracted all data. Study abstraction forms consisted of fields including (1) the author and year the study was published; (2) program participants (mentees and mentors); (3) model of mentorship; (4) program objectives; (5) description of program components; (6) program evaluation including whether the program was evaluated and methods of evaluation; and (7) results of evaluation. Additionally, we evaluated facilitators and/or barriers including costs to these programs.

\section{RESULTS}

\section{Study Selection}

We retrieved 3625 citations in June 2017 and an additional 436 in November 2018 for a total of 4061 citations. After screening for duplicate records, 3743 remained. A total of 3499 records were excluded based on title and abstract, and 244 underwent full text review. In total, 30 papers describing 29 programs met our inclusion criteria (Fig. 1). Two papers described the same mentoring program ${ }^{10,11}$.

\section{Program Description}

The description of these programs including participants, mentorship model, program objectives, and program components is found in a table included in the supplemental material online.

\section{Mentoring Models}

The most common model of mentorship used was the traditional dyad model, which was used exclusively by 16 programs $^{10-25}$.

Four programs used a group model of mentorship ${ }^{26-29}$. Three of these utilized traditional group mentorship wherein faculty members would meet with groups of medical students periodically ${ }^{26,27,29}$. Another program used what they described as a "tiered" group mentorship model in which the mentors were a combination of faculty, resident, and fourth year medical students and the mentees were junior medical students ${ }^{28}$. The goal of the tiered model was to offer mentorship across the spectrum of academic position so that the residents and fourth year medical students who were serving as mentors to more junior students could also receive mentorship from the faculty. An additional program that used multiple models of mentorship also described a "vertical" approach with a similar goal of providing mentorship across the spectrum of academic position ${ }^{30}$.

Seven of the 28 programs used a combination of models, specifically dyad and group mentoring ${ }^{2,30-35}$. Four of these programs were part of larger longitudinal initiatives by the medical school within the context of an advisory college/dean program. In these programs, faculty members were often assigned a group of medical students whom they met with in groups and individually to offer mentorship and assist with professional development and career planning ${ }^{2,30,32,33}$. In general, group mentoring was used to discuss broadly applicable topics, which then allowed the one-on-one meetings to be more specific to the individual needs of the student.

\section{Program Objectives}

Most programs stated broad objectives including assisting medical students with career development/career planning ${ }^{2}$, $10,12,14,30$, professional development $11,12,19,23,24,26,30,32,33$, and well-being ${ }^{29,32}$. 


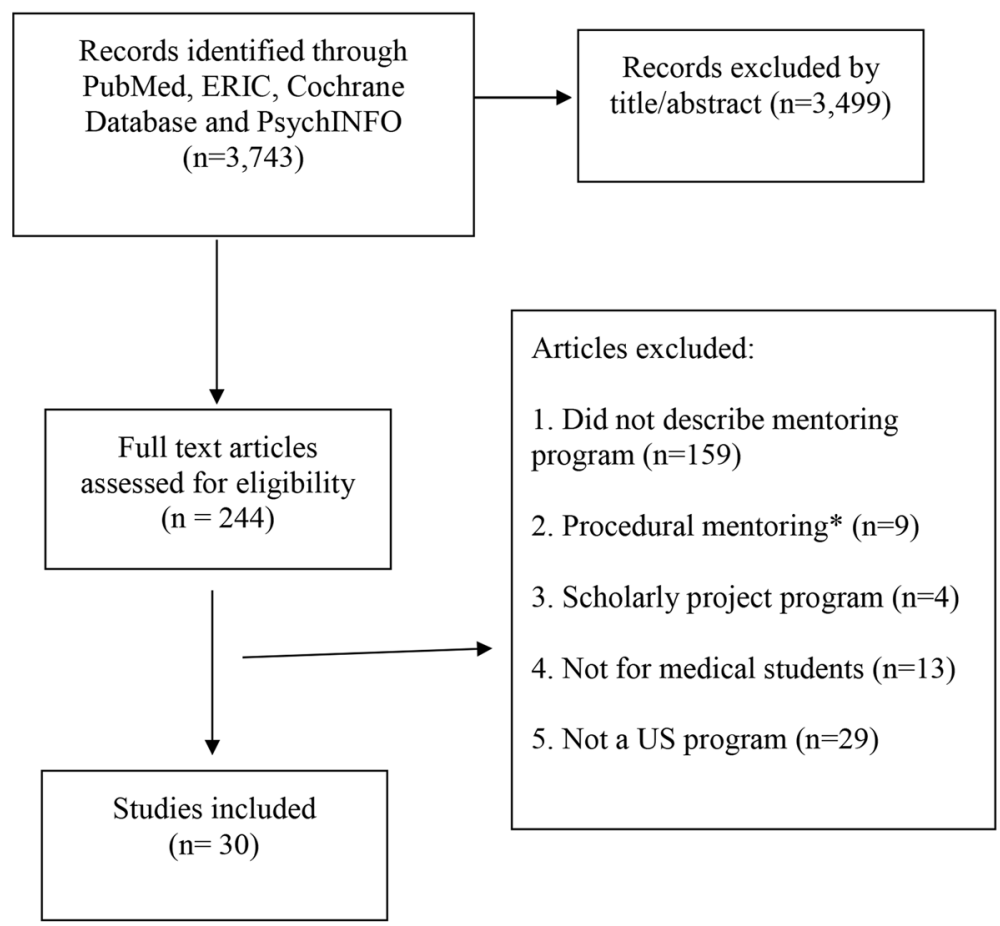

*Procedural mentoring defined as mentoring for a specific clinical skill

Fig. 1 PRISMA diagram.

Many of the programs had the specific objective of mentoring either underrepresented minorities (URM) or female medical students. Seven of the programs were for URM students ${ }^{12,13,21,29,31,35,36}$. The majority of these were only for URM medical students ${ }^{12,13,21,29,31}$; however, two of the programs were part of a larger initiatives involved mentees from pre-medical students through faculty ${ }^{35,36}$. There were two programs whose stated objectives were to provide mentoring to female medical students ${ }^{22,27}$.

Tweleve ${ }^{14,15,17,18,20-23,25,28,34,37}$ provided mentorship that was specific to a certain field of medicine with the objective of recruiting students and providing career and research mentorship for that specialty.

\section{Program Evaluation}

Seven of the programs reported objective outcomes related to clerkship grades, research productivity, and residency match (Table 1). Five were subspeciality specific ${ }^{15,17,18,23,34}$, one focused on URM students ${ }^{36}$, and one program was aimed at developing a pipeline of URM students in a surgical subspeciality ${ }^{21}$. Two studies reported a significant increase in presentations and publications ${ }^{18,34}$. One program for primary care reported that in each year of the program, more students who participated in the mentoring program matched into a primary care specialties compared to non-participating students from the same medical school graduating class (year $187.5 \%$ vs $55.8 \%$ and year $278.9 \%$ vs $35.9 \%)^{15}$. A program that was part of the obstetrics and gynecology clerkship found an increase in the number of students applying to the obstetrics and gynecology residency program at the same institution (from 2 applications prior to 11 applications after implementation of the program) ${ }^{17}$. A surgical program reported that $50 \%$ of the participants received a grade of honors during their surgical clerkship versus only $31.5 \%$ of non-participants $(p \text { value } 0.05)^{23}$. A neurology specific mentoring program demonstrated an increase in the number of students entering neurology from an average of 2.8 per year to 7.5 per year ${ }^{34}$. A program for students interested in radiation oncology reported that over a 10 -year period, they had $100 \%$ match rate for the students in the program compared to a national match rate of $85.1 \%$ additionally as an indicator of success, they reported that for each year more student participated with 3 students participating in the first year of the program and 11 students in the 10th year of the program ${ }^{18}$. A program for URM students within otolaryngology found that six of the seven students who applied to otolaryngology residency matched successfully and that the URM representation among residents at the host institution increased from $9 \%$ of the total residents prior to the program to $16 \%$ after the program ${ }^{21}$. Finally, one program for URM students tracked academic outcomes and found that the percent of URM students obtaining honors increased in three of the five required clerkships compared to prior to the initiation of the program ${ }^{36}$.

Nineteen of the programs provided subjective outcome measures of success (Table 2). As is true of much of the mentorship literature ${ }^{39}$, the evaluations of the programs were largely measured by ratings of satisfaction. In general, the students rated the programs highly. 
Table 1 Program Evaluation Methods and Evaluation Results for Programs with Objective Outcomes

\begin{tabular}{|c|c|c|}
\hline Study, year & Program evaluation & Evaluation results \\
\hline Nellis, $2016^{21}$ & $\begin{array}{l}\text { Survey and } \\
\text { retrospective review }\end{array}$ & $\begin{array}{l}\text { - Students rated the mentorship highly } 4.85 / 5 \\
\text { - } 7 / 15 \text { students applied to otolaryngology residencies } \\
\text { - } 6 / 7 \text { matched successfully } \\
\text { - URM* representation among the residents at the host institution } \\
\text { increased from } 9 \% \text { of the total residents before the program to } 16 \%\end{array}$ \\
\hline Day, $2016^{23}$ & Survey and retrospective review & $\begin{array}{l}-50 \% \text { of participants received a grade of honors during their surgical } \\
\text { clerkship vs. } 31.5 \% \text { non-participants }(p \text { value }=0.05) \\
\text { - Participants reported that their resident mentor strongly impacted } \\
\text { their decision to pursue surgery }\end{array}$ \\
\hline Sobbing, $2015^{23}$ & Survey and retrospective review & $\begin{array}{l}\text { - Increase in the number of medical students applying to the residency } \\
\text { program vs. prior to the program ( } 2 \text { to } 11 \text { applicants) } \\
\text { - } 56 \% \text { reported receiving advice on personal development/support } \\
\text { - } 40 \% \text { reported feeling well/extremely well connected with their mentor }\end{array}$ \\
\hline Zuzarregui, $2015^{34}$ & Retrospective review & $\begin{array}{l}\text { - Increase in the number of medical students entering neurology from an } \\
\text { average of } 2.8 \text { per year to } 7.5 \text { per year }(p \text { value }<0.05) \\
\text { - Increased the number of medical student research projects, posters and } \\
\text { publications vs. prior to the program from } 7 \text { to } 22(p \text { value }<0.05)\end{array}$ \\
\hline Hirsch, $2015^{18}$ & Retrospective review & $\begin{array}{l}\text { - } 17 / 58 \text { participants }(29.3 \%) \text { applied to and matched into radiation } \\
\text { oncology ( } 100 \% \text { match rate) vs. national match rate of } 85.1 \% \text { ( } p \text { value } 0.14) \\
\text { - Over } 10 \text { years mentee research productivity: } 53 \text { publications, } \\
75 \text { national presentations, } 10 \text { national awards }\end{array}$ \\
\hline Indyk, $2011^{18}$ & $\begin{array}{l}\text { Post-residency match survey } \\
\text { and annual focus groups }\end{array}$ & $\begin{array}{l}\text { - For each year of the program, participants were more likely to match } \\
\text { into primary care vs. non-participants (year } 187.5 \% \text { vs } 55.8 \% \\
\text { and year } 278.9 \% \text { vs } 35.9 \% \text { ) } \\
\text { - } 61.0 \% \text { of participants reported that the mentor influenced their career } \\
\text { - Themes from qualitative analysis: (1) impact on the understanding of } \\
\text { primary care and (2) facilitators and inhibitors of the mentoring relationship }\end{array}$ \\
\hline Johnson, $1998^{36}$ & Retrospective review & $\begin{array}{l}\text { Percent of URM students obtaining honors increased for } 3 \text { of the } 5 \text { required } \\
\text { third-year clerkships vs. prior to the program }\end{array}$ \\
\hline
\end{tabular}

*Underrepresent minorities

Two programs used the Association of American Medical Colleges (AAMC) graduation questionnaire to help evaluate their programs and were able to track changes over time versus national averages. One institution, using the AAMC data, reported increases in satisfaction with both faculty mentoring from $75.6 \%$ prior to the program to $87.5 \%$ after the program and career planning from $67.5 \%$ prior to the program to $82.9 \%^{11}$. Another program reported that $79.4 \%$ of their students were satisfied/very satisfied with faculty mentoring compared to $58.1 \%$ of their students prior to the program and a national average of $65.4 \%{ }^{2}$.

In general, the programs that were smaller and subspeciality specific provided more objective measures of success. $\mathrm{Six}^{15,17,18,21,23,34}$ of the 12 subspeciality programs offered objective outcomes measures whereas none of the subspeciality programs with greater than 100 participating students $^{14,28,37}$ or the programs that enrolled all medical students in a school provided objective outcomes measures.

\section{Program Cost}

Many of the studies discussed the costs of these programs. For those that were part of an advisory dean/college programs, faculty salary support was a significant cost. One program listed faculty salary support as $\$ 500,000$ per year with an additional $\$ 80,000$ in other costs ${ }^{11}$. For another program, the Dean's office provided $25 \%$ salary support to each of the mentors ${ }^{24}$. Other advisor dean/college programs report salary support of $15-20 \%$ for the main faculty ${ }^{32,33}$. Of note, these larger and more costly programs did not report on any objective outcomes measures of success, although one did provide some pre/post data that demonstrated an overall improvement in satisfaction with faculty mentorship and career planning ${ }^{11}$. Four of the programs were funded by external grants, ${ }^{15,28,35,37}$ one of which was a small grant of $\$ 500$ from a national speciality organization that was matched by the department at the local institution ${ }^{28}$.

While several programs used students and/or residents as mentors, two specifically commented on the costs aspect of using more junior mentors. One program that used fourth year medical students as mentors commented that using students helped reduce $\operatorname{costs}^{30}$. A second program that relied on one faculty and one resident to oversee the program commented that each invested approximately $15 \mathrm{~h}$ per month on the program ${ }^{34}$ therefore, having the resident effectively doubled the hours invested.

\section{Barriers of Programs}

Beyond costs, several of the papers described other barriers. Two articles cited faculty members' busy schedules as barriers, ${ }^{19,27}$ while those that utilized residents and students as mentors noted competing demands and responsibilities ${ }^{17,30}$.

For mentoring programs that were aimed at URM students, the small number of URM faculty was reported as a barri$\mathrm{er}^{31,36}$. One program attempted to address this by utilizing non-URM faculty mentors ${ }^{31}$. Another program recruited URM physician mentors from local private practices ${ }^{12}$ in order to expand the number of possible mentors. 
Table 2 Program Evaluation Methods and Evaluation Results for Programs with Subjective Outcomes

\begin{tabular}{|c|c|c|}
\hline Study, year & Program evaluation & Evaluation results \\
\hline $\begin{array}{l}\text { Brueckner-Collins, } \\
2018^{25}\end{array}$ & Survey & $\begin{array}{l}\text { - Participants provided positive comments } \\
\text { - Noted that connections made with senior faculty mentors } \\
\text { later helped advance their career }\end{array}$ \\
\hline Andre, $2017^{30}$ & Annual all-student survey & $\begin{array}{l}\text { - Year to year increase in satisfaction with medical school } \\
\text { experience }(p \text { value }<0.0001) \\
\text { - } 94.3 \% \text { of students felt the groups and } 4 \text { th year medical } \\
\text { student mentors provided them with peer support }\end{array}$ \\
\hline Maursetter, $2016^{20}$ & Survey & $\begin{array}{l}\text { - Students rated the mentoring experience a mean of } 7.1 / 10 \\
\text { - } 70 \% \text { had }>10 \text { interactions with their mentor in a year } \\
\text { - } 41.6 \% \text { increase in interest in a nephrology fellowship } \\
\text { vs prior to participating }\end{array}$ \\
\hline Khan, $2016^{22}$ & Survey & - $80 \%$ of mentees felt that surgeons had a manageable lifestyle \\
\hline DeFilippis, $2015^{27}$ & Survey & $\begin{array}{l}\text { - } 71 \% \text { of participants ranked the program as } 4 \text { or } 5 / 5 \text { for satisfaction } \\
\text { - } 77 \% \text { felt the program provided opportunities for mentorship } \\
\text { - } 82 \% \text { felt it filled an institutional need }\end{array}$ \\
\hline Weiner, $2014^{38}$ & Survey & $\begin{array}{l}\text { - } 28 \% \text { of students used the database } \\
\text { - } 46 \% \text { of participants felt it helped them identify a mentor }\end{array}$ \\
\hline Stein, $2013^{37}$ & Pre and post-survey & $\begin{array}{l}\text { - Increase in knowledge of child and adolescent psychiatry ( } p \text { value }< \\
0.01) \\
\text { - Increase in perception of mentorship for research guidance ( } p \text { value } \\
<0.05) \\
\text { - Increase in perception of mentorship for career guidance }(p \text { value }<0.05 \text { ) } \\
\text { - No change in desire to enter child or adolescent psychiatry }\end{array}$ \\
\hline Kman, $2013^{28}$ & Survey & $\begin{array}{l}\text { - Increase in the number of medical students who could identify } \\
\text { a mentor vs prior to the program }(77.6 \% \text { vs } 28 \%) \\
\text { - } 70 \% \text { had more interest in emergency medicine as a career } \\
\text { vs. prior to participation }\end{array}$ \\
\hline Drusin, $2013^{19}$ & Survey & $\begin{array}{l}\text { - } 79.5 \% \text { of students met with their advisor at least once } \\
\text { - } 66.7 \% \text { were satisfied with their advisor }\end{array}$ \\
\hline $\begin{array}{l}\text { Thomas-Squance, } \\
2011^{29}\end{array}$ & Survey & $\begin{array}{l}\text { - } 89 \% \text { rated the program as valuable } \\
\text { - } 84 \% \text { felt it was relevant to professional development } \\
\text { - } 54 \% \text { valued meeting mentors }\end{array}$ \\
\hline Oelschlager, $2011^{24}$ & Survey & $\begin{array}{l}\text { - } 48.1 \% \text { reported that they had contact with the mentor once per quarter } \\
\text { - } 73 \% \text { reported that their mentor was helpful/very helpful }\end{array}$ \\
\hline Drolet, $2010^{10 *}$ & Anecdotal evidence & - Students report satisfaction with the program \\
\hline Fleming, $2013^{11} *$ & $\mathrm{AAMC} \dagger$ Graduation Questionnaire & $\begin{array}{l}\text { - Increase in satisfaction with faculty mentoring vs prior to the } \\
\text { program } 87.5 \% \text { from } 75.6 \%(p \text { value } 0.81) \text { and career planning } 82.9 \% \\
\text { from } 67.5 \%(p \text { value }=0.037)\end{array}$ \\
\hline Coates, $2008^{2}$ & $\begin{array}{l}\text { Internal survey and AAMC Graduation } \\
\text { Questionnaire }\end{array}$ & $\begin{array}{l}\text { - Compared to before the program: (1) increase in number of students } \\
\text { who identified a career mentor vs prior to the program }(73 \% \text { vs } 37 \%) \\
\text { and (2) increase in the number of students satisfied/very satisfied with } \\
\text { faculty mentoring vs prior to the program }(79.4 \% \text { vs } 58.1 \% \text { vs } 65.4 \% \\
\text { national average) }\end{array}$ \\
\hline Macaulay, $2007^{33}$ & Survey & - $89 \%$ of respondents reported the Advisor Dean program as valuable \\
\hline Kosoko-Lasaki, $2006^{35}$ & Survey & $\begin{array}{l}\text { - } 89 \% \text { agree that the mentoring program is effective } \\
\text { - Medical students reported that mentors helped with their choice of } \\
\text { residency programs }\end{array}$ \\
\hline Coates, $2004^{14}$ & Qualitative survey & - $67 \%$ of students offered positive comments about the program \\
\hline Abernethy, $1999^{31}$ & Survey & $\begin{array}{l}\text { - Students met with their mentor an average of } 3 \text { times per year } \\
\text { - Student satisfaction with mentor mean rating } 5.1 \text { out of } 7\end{array}$ \\
\hline Flach, $1982^{16}$ & Survey & - $63 \%$ of students were satisfied with their mentor \\
\hline
\end{tabular}

*Drolet and Fleming articles represent the same program described in two separate papers; therefore, they have been listed together in the table †Association of American Medical Colleges

Some programs cited mentor skill development as a barrier. One program using residents as primary mentors reported that they often lacked optimal mentorship training ${ }^{17}$. Several programs included a variety of trainings aimed at improving mentorship quality ${ }^{24,31}$. Two programs provided mentors with written guidelines delineating mentorship roles ${ }^{14,28}$. One program offered an introductory training session for both mentors and mentees in which the objectives of the program were explained and expectations of both mentor and mentees were discussed $^{25}$. Finally, one program reported that while there was no formal training, the mentors met monthly to discuss "best practices."2

\section{DISCUSSION}

Our systematic review identified 30 separate articles describing 29 mentorship programs for medical students and demonstrated several important themes. The traditional dyad model of mentorship was used most commonly, which is consistent with previous literature ${ }^{6,39,40}$. The second most common model was a combination of dyad and group mentorship. Many of these programs described that group sessions were used to discuss broadly applicable issues and one-on-one sessions were used for the personal needs of the mentee. Given that both faculty time and salary support were commonly cited constraints, using a combination of mentorship models may 
reduce faculty time and associated costs by improving the efficiency of individual meetings. While there may be improvement in efficiency of mentorship, of the seven programs with objective measures of success five used exclusive dyad mentorship $^{15,17,18,21,23}$ which suggests that the intensity of traditional dyad mentorship may result in more tangible measures of success.

Notably, none of the programs used a traditional peer model of mentorship. While some of the programs referenced peer mentoring ${ }^{28,30}$, these were not traditional peer mentoring programs in which two individuals at the same level of training provide mentorship to each other. Instead, these programs assigned fourth year students along with faculty and/or residents to help mentor more junior level students and applied a tiered model of mentorship to provide mentorship across academic positions. Other programs that used group mentoring commented that one benefit of group mentoring was that the students developed peer relationships, which could be used as a source of support ${ }^{27-29}$. The literature has documented that peer mentorship is occurring in medical schools, ${ }^{1}$ and it is likely that peer mentorship plays an important role in medical education, but it appears to be to an underutilized model in formal mentorship programs. This is in contrast to models of mentorship for physicians wherein peer models are more common ${ }^{39}$. Additionally, given that most of the associated costs were due to faculty salary support, further use of peer and/or senior student mentorship might help minimize this barrier to development of mentorship programs.

Mentorship of specific subsets of medical students (i.e., a certain race, ethnicity, gender, or clinical area of interest) emerged as a theme throughout our review with seven programs providing mentorship to URM students ${ }^{12,13,21,29,31,35,36}$, two programs to female students $\mathrm{s}^{22,27}$, and 12 programs focusing specific clinical specialities ${ }^{14,15,17,18,20-23,25,28,34,37}$. It is wellestablished that individuals from some racial minorities remain underrepresented in medicine $e^{41,42}$. Additionally, mentorship programs may be a key factor in improving the recruitment and retention of URM physicians, as demonstrated by the success that one of the programs had at increasing the number of URM residents in their residency after the initiation of the mentorship program ${ }^{21}$. It was therefore surprising that the majority of these URM mentoring programs are over 10 years old $^{12,13,31,35,36}$ and that there was a lack of more modern programs aimed at reducing the known disparities in URM physicians' recruitment, promotion, and retention. Although the current literature does not assess whether improved mentorship of URM physicians may help reduce these disparities, this is an important area for future study.

Women also remain underrepresented in academic medicine, particularly in leadership positions and surgical fields ${ }^{43}$ and are less likely to have mentors compared to their male counterparts ${ }^{44,45}$. As such, the existence of mentorship programs for female students is notable. Of note, these programs used group mentorship ${ }^{27,28}$ to counteract the lack of senior female physicians serving as mentors. However, prior work has found that preference for gender concordance may be overstated ${ }^{40,46}$ and that preferences for other factors germane to the mentoring relationship such as shared career interest may matter more ${ }^{47}$. Additionally, there may be limitations to gender concordant mentoring. In fact, one program planned to no longer use female-only groups after receiving feedback from students that felt they were unable to find a mentor in the all women groups $^{28}$. As gender roles continue to evolve in society, the importance of gender concordance may continue to decline. This may occur as more women assume leadership positions that have historically been more occupied by men, and more men gain experience with mentorship of women across the academic spectrum, including in fields that have traditionally had fewer women. Overall, the results of our review and others suggest that academic communities are making efforts to improve mentorship of women, and that a potential lack of senior female mentors should not be considered a barrier.

The lack of objective outcomes and comparison data is a common theme in the mentorship literature ${ }^{39}$ and makes it difficult to assess the long-term impact of these mentorship programs. Smaller programs that were developed for specific clinical interests were able to demonstrate objective outcomes based on recruitment, publications, or improved grades. For the remaining programs, the vast majority, including the larger and more costly programs, measured student satisfaction as the main outcome. While student satisfaction is important to measures of medical school quality and incorporated into evaluation tools from the AAMC Graduation Questionnaire and LCME, having objective outcomes data such as residency match data, board scores, or clinical evaluations would offer a more standard evaluation of success and possible help justify the cost of these programs. However, it is important to remember that many aspects of mentorship may not lend themselves to objective quantitative measures of success, and that even without objective outcomes, these programs are likely to have a positive impact on the participants.

While the cost of several of these programs was significant, the upfront investment may be justified if mentorship can help reduce burnout, given the significant cost of having to extend medical school training. It was therefore disappointing that despite three studies ${ }^{10,29,32}$ noting student wellness as an objective, these issues were not assessed as an outcome in any program. As medical student burnout continues to rise ${ }^{48}$, effective ways to improve wellness should be developed. While mentorship of physicians has been associated with career satisfaction and faculty retention ${ }^{3}$, to our knowledge, there is no data that looks of the impact of mentorship on medical student burnout. While it is unlikely that mentorship alone will reduce burnout without more comprehensive and systemic reforms, it may help improve factors associated with burnout including isolation and feelings of powerlessness. Future research to explore the use of mentoring to enhance student wellness would be a significant contribution to the mentorship literature and may help justify the cost of these large mentorship programs. 
One possible limitation our paper is the subjective nature of mentorship, the variety of forms that mentorship can take, and its inherent potential for overlap with advising. While we applied our stated and previously published definition of mentorship to our search protocol, we are limited by the word choice that the authors of each manuscript choose to describe the programs and relationships between the students and proposed mentors. We do not feel that this potential limitation influenced our results, as the majority of our studies describe a similar definition of mentorship. Additionally, we limited our review to programs offered within the USA as the training structure in the USA is unique compared to other countries ${ }^{49}$. This is consistent with previous reviews on mentorship of physicians ${ }^{39}$ but may limit the generalizability of our results internationally. Another possible limitation is that additional data may exist which meet our inclusion criteria but was unable to be included if results were not stratified with medical student-specific data.

\section{CONCLUSION}

Our review describes a range of successful mentorship programs for medical students. The most common mentorship model is the dyad approach, which may also produce greater success in terms of measureable outcomes, while group mentorship may help to control cost of larger mentorship programs. Additionally, medical schools recognize the need for mentorship to help address the dearth of URM physicians in medicine as a whole, and the lack of women in specific fields and leadership positions. Smaller clinically focused programs are more likely to produce measurable results, while larger programs demonstrate that effective mentoring benefits students' overall medical school experience and career development. Overall, our review has demonstrated that no clear best practices for medical student mentorship exist in the literature. One conclusion, therefore, is that institutions can individualize their mentorship programs and models to available resources and goals. Additionally, our results demonstrate the importance of further development and objective evaluation of medical student mentorship programs to more effectively enhance the experience and development of medical students across the spectrum.

Corresponding Author: Amy H. Farkas, MD, MS; Division of General Internal Medicine Medical College of Wisconsin, Milwaukee VA Medical Center, 5000 W National Ave, Milwaukee, WI 53295, USA (e-mail: ahfarkas@mcw.edu).

\section{Compliance with Ethical Standards:}

Conflict of Interest: The authors declare that they do not have a conflict of interest.

\section{REFERENCES}

1. Pinilla S, Nicolai $\mathbf{L}$, Gradel $\mathbf{M}$, et al. Undergraduate Medical Students Using Facebook as a Peer-Mentoring Platform: A Mixed-Methods Study. JMIR Med Educ 2015;1(2):e12.
2. Coates WC, Crooks K, Slavin SJ, Guiton G, Wilkerson L. Medical school curricular reform: fourth-year colleges improve access to career mentoring and overall satisfaction. Acad Med 2008;83(8):754-760.

3. Sambunjak D, Straus SE, Marusic A. Mentoring in academic medicine: a systematic review. JAMA. 2006;296(9):1103-1115.

4. Liasion Committee on Medical Education. Functions and Structure of a Medical School: Standards for Accrediation of Medical Education Programs Leading to the MD Degree. 2018; http://lcme.org/publications/. Accessed June 16, 2019

5. Aagaard EM, Hauer KE. A cross-sectional descriptive study of mentoring relationships formed by medical students. J Gen Intern Med 2003;18(4):298-302.

6. Frei E, Stamm M, Buddeberg-Fischer B. Mentoring programs for medical students-a review of the PubMed literature 2000-2008. BMC Med Educ 2010;10:32.

7. Buddeberg-Fischer B, Herta $\mathbf{K D}$. Formal mentoring programmes for medical students and doctors-a review of the Medline literature. Med Teach 2006;28(3):248-257.

8. Association of American Medical Colleges. Results of the 2017 Medical School Enrollment Survey; Washington, DC; 2018. https://store.aamc. org/downloadable/download/sample/sample_id/183/

9. Beech BM, Calles-Escandon J, Hairston KG, Langdon SE, LathamSadler BA, Bell RA. Mentoring programs for underrepresented minority faculty in academic medical centers: a systematic review of the literature. Acad Med 2013;88(4):541-549.

10. Drolet BC, Rodgers S. A comprehensive medical student wellness program-design and implementation at Vanderbilt School of Medicine. Acad Med 2010;85(1):103-110.

11. Fleming A, Cutrer W, Moutsios S, et al. Building learning communities: evolution of the colleges at Vanderbilt University School of Medicine. Acad Med 2013;88(9):1246-1251.

12. Peterson SE, Carlson P. A mentorship program for minority students. Acad Med 1992;67(8):521.

13. Cregler LL. A second minority mentorship program. Acad Med 1993;68(2): 148.

14. Coates WC, Ankel F, Birnbaum A, et al. The virtual advisor program: linking students to mentors via the world wide web. Acad Emerg Med 2004;11(3):253-255.

15. Indyk D, Deen D, Fornari A, Santos MT, Lu WH, Rucker L. The influence of longitudinal mentoring on medical student selection of primary care residencies. BMC Med Educ 2011;11:27.

16. Flach DH, Smith MF, Smith WG, Glasser ML. Faculty mentors for medical students. J Med Educ 1982;57(7):514-520.

17. Sobbing J, Duong J, Dong F, Grainger D. Residents as Medical Student Mentors During an Obstetrics and Gynecology Clerkship. J Grad Med Educ 2015;7(3):412-416.

18. Hirsch AE, Agarwal A, Rand AE, et al. Medical student mentorship in radiation oncology at a single academic institution: A 10-year analysis. Pract Radiat Oncol 2015;5(3):e163-168.

19. Drusin LM, Gerber LM, Miller CH, Storey-Johnson CL, Ballard BL. An advisory program for first- and second-year medical students: the Weill Cornell experience. Med Educ Online 2013;18:22684.

20. Maursetter LJ, Stern LD, Sozio SM, et al. Enhancing Nephrology Career Interest through the ASN Kidney TREKS Program. J Am Soc Nephrol 2016;27(6): 1604-1607.

21. Nellis JC, Eisele DW, Francis HW, Hillel AT, Lin SY. Impact of a mentored student clerkship on underrepresented minority diversity in otolaryngologyhead and neck surgery. Laryngoscope. 2016;126(12):2684-2688.

22. Khan S, Ferrada P. Empowering Surgical Residents as Mentors: A Pilot Program for Female Medical Students. Am Surg 2016;82(11):313-314.

23. Day KM, Schwartz TM, Rao V, et al. Medical student clerkship performance and career selection after a junior medical student surgical mentorship program. Am J Surg 2016;211(2):431-436.

24. Oelschlager AM, Smith S, Tamura G, Carline J, Dobie S. Where do medical students turn? The role of the assigned mentor in the fabric of support during medical school. Teach Learn Med 2011;23(2):112-117.

25. Brueckner-Collins JK, Stratton TD, Conigliaro RL. Inspiring the next generation of academic physicians: the academic health careers program. Med Educ online 2018;23(1): 1530559.

26. Kalet A, Krackov S, Rey M. Mentoring for a new era. Acad Med 2002;77(11):1171-1172.

27. DeFilippis E, Cowell E, Rufin M, Sansone S, Kang Y. Innovative mentoring for female medical students. Clin Teach 2016;13(5):381-382.

28. Kman NE, Bernard AW, Khandelwal S, Nagel RW, Martin DR. A tiered mentorship program improves number of students with an identified mentor. Teach Learn Med 2013;25(4):319-325. 
29. Thomas-Squance GR, Goldstone $\mathbf{R}$, Martinez A, Flowers LK Mentoring of students from under-represented groups using emotionally competent processes and content. Med Educ 2011;45(11):1153-1154.

30. Andre C, Deerin J, Leykum L. Students helping students: vertical peer mentoring to enhance the medical school experience. BMC Res Note 2017; 10(1): 176

31. Abernethy AD. A mentoring program for underrepresented-minority students at the University of Rochester School of Medicine. Acad Med 1999;74(4):356-359.

32. Murr AH, Miller C, Papadakis M. Mentorship through advisory colleges. Acad Med 2002;77(11):1172-1173.

33. Macaulay W, Mellman LA, Guest DO, Nichols GL, Haddad J Jr. Puchner PJ. The advisory dean program: a personalized approach to academic and career advising for medical students. Acad Med 2007;82(7):718-722.

34. Zuzuarregui JR, Hohler AD. Comprehensive Opportunities for Research and Teaching Experience (CORTEX): A mentorship program. Neurology. 2015;84(23):2372-2376.

35. Kosoko LO, Sonnino, R E, Voytko, M L. Mentoring for women and underrepresented minority faculty and students: experience at two institutions of higher education. J Natl Med Assoc 2006;98(9):14491459 .

36. Johnson JC, Jayadevappa R, Taylor L, Askew A, Williams B, Johnson B. Extending the pipeline for minority physicians: a comprehensive program for minority faculty development. Acad Med 1998;73(3):237244.

37. Stein JA, Althoff $\mathbf{R}$, Anders T, et al. Does early mentorship in child and adolescent psychiatry make a difference? The Klingenstein ThirdGeneration Foundation Medical Student Fellowship Program. Acad Psychiatry 2013;37(5):321-324.

38. Weiner J, Small AC, Lipton LR, et al. Establishing an online mentor database for medical students. Med Educ 2014;48(5):542-543.

39. Kashiwagi DT, Varkey P, Cook DA. Mentoring programs for physicians in academic medicine: a systematic review. Acad Med 2013;88(7):1029 1037.
40. Farkas AH TR, Bonifacino E, Tilstra SA, Corbelli JA. Mentoring Women in Academic Medicine: A Systematic Review. In. Abstract presented at the Society of General Internal Medicine National Meeting, Denver CO, 2018.

41. Nivet MA, Castillo-Page L. Diversity in the Physician Workforce: Facts \& Figures. Association of the American Medical Colleges; Washington, DC; 2014. http://www.aamcdiversityfactsandfigures.org/

42. Association of American Medical Colleges. Altering the Course: Black Males in Medicine. Association of American Medical Colleges; Washington D.C.; 2015.

43. Lautenberge D, Dandar, VM., Raezer, CL., Sloane, RA. The State of Women in Academic Medicine: The Pipeline and Pathways to Leadership. Association of American Medical Colleges; Washington, DC; 2014.

44. Osborn EH, Ernster VL, Martin JB. Women's attitudes toward careers in academic medicine at the University of California, San Francisco. Acad Med 1992;67(1):59-62.

45. Stamm M, Buddeberg-Fischer B. The impact of mentoring during postgraduate training on doctors' career success. Med Educ 2011;45(5):488-496.

46. DeCastro R, Griffith KA, Ubel PA, Stewart A, Jagsi R. Mentoring and the career satisfaction of male and female academic medical faculty. Acad Med 2014;89(2):301-311.

47. Carapinha R, Ortiz-Walters R, McCracken CM, Hill EV, Reede $\boldsymbol{J Y}$. Variability in Women Faculty's Preferences Regarding Mentor Similarity: A Multi-Institution Study in Academic Medicine. Acad Med 2016;91(8): 1108-1118.

48. Dyrbye LN, West CP, Satele D, et al. Burnout among U.S. medical students, residents, and early career physicians relative to the general U.S. population. Acad Med 2014;89(3):443-451.

49. Weggemans MM, van Dijk B, van Dooijeweert B, Veenendaal AG, ten Cate $\mathbf{O}$. The postgraduate medical education pathway: an international comparison. GMS J Med Educ 2017;34(5):Doc63.

Publisher's Note Springer Nature remains neutral with regard to jurisdictional claims in published maps and institutional affiliations. 